
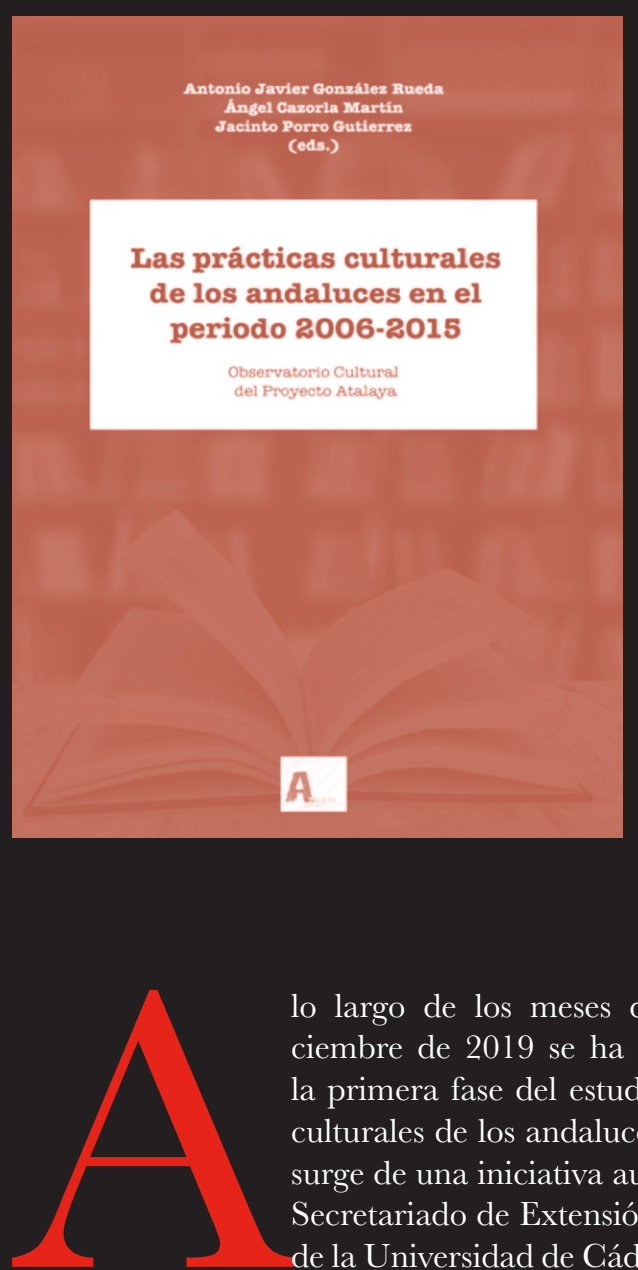

lo largo de los meses de enero a diciembre de 2019 se ha llevado a cabo la primera fase del estudio de prácticas culturales de los andaluces. Este trabajo surge de una iniciativa auspiciada por el Secretariado de Extensión Universitaria de la Universidad de Cádiz, que desde el año 2005 coordina a un grupo de investigadores de la Red de Universidades Públicas de Andalucía, dando lugar al Observatorio Atalaya de Prácticas Culturales. La orientación de este equipo, así como de las publicaciones nacidas a su amparo, ha sido la de crear productos en los cuales indagar sobre los hábitos y prácticas culturales de los andaluces, ya sea en el ámbito universitario como para el total de la población de esta comunidad, proyectando sus resultados al papel de los gestores culturales como responsables de la implementación de políticas de gestión cultural.

La obra que reseñamos es la última publicación de este Observatorio Atalaya, en la cual se indaga acerca de los hábitos y prácticas de los andaluces en el periodo 2006-2015. Es este un ambicioso trabajo en el que, con el precedente de la investigación y publicación previa llevada a cabo por el Catedrático de Sociología de la Universidad de Valencia, D. Antonio Ariño Ramis, se utilizan los datos de la Encuesta

\section{Las prácticas culturales de los andaluces en el periodo 2006-2015}

Equipo de investigadores sociales de las Universidades Andaluzas

Editores: Dr. Antonio Javier González Rueda, Dr. Ángel Cazorla Martín, Dr. Jacinto Porro Gutiérrez. Investigación comisionada por:

Universidad de Cádiz (UCA) y las Universidades Públicas de Andalucía, en el marco del Observatorio Cultural del Proyecto Atalaya.

ISBN 978-84-09-16868-2

Diciembre 2019, Cádiz

364 páginas

Hábitos y Prácticas Culturales (EHPC). Este es un estudio demoscópico llevado a cabo por el Ministerio de Cultura y Deporte en los años de 2006, 2011 y 2015. Dicha encuesta es el más importante esfuerzo en el ámbito del análisis de los hábitos y prácticas culturales de los españoles, siendo un trabajo que nos permite mediante su metodología un análisis longitudinal de las continuidades y cambios en el consumo cultural y las prácticas culturales de la población de este país. Dado que dicha EHPG presenta resultados a nivel general y autonómico, el Observatorio Atalaya de Prácticas Culturales lleva a cabo con su red de investigadores el análisis y segmentación de la encuesta en las tres ediciones señaladas, todo ello con el claro objetivo de dibujar la evolución en las pautas de consumo cultural de los andaluces. Para cada uno de los bloques temáticos se ha propuesto un análisis en el cual describir las principales variables explicativas a nivel sociodemográfico. De este modo, desde una óptica eminentemente evolutiva, esta publicación presenta resultados novedosos, a los que no había llegado el estudio del Ministerio de Cultura y Deporte en sus distintas ediciones, en tanto que su objeto de análisis era el total de la población española.

En los nueve capítulos de esta obra se analizan los equipamientos, hábitos y prácticas culturales de los andaluces, comenzando en el primero por los medios de comunica- 
ción, TV y radio. El segundo describe los hábitos de lectura, ya sea de libros impresos y digitales, como lectura de prensa y asistencia a bibliotecas. El tercero analiza el consumo musical y el cuarto el consumo de vídeo, muy importantes en tanto que los últimos años suponen alteraciones profundas en los modos de acceso y consumo de estos bienes culturales. En el quinto capítulo se aborda un análisis del uso y consumo de artes escénicas, mientras que en el sexto se centra en el uso de ordenadores y nuevos dispositivos como tabletas e Internet. El séptimo se adentra en el ocio y otras prácticas culturales de los andaluces, más orientadas a la formación y expresión artística, a la vez que el octavo indaga respecto al patrimonio cultural y la asistencia a museos. Por último, el noveno y último capítulo muestra el estudio en ámbito comparado de los hábitos y prácticas culturales de los andaluces en relación a la población española.

Los resultados globales expuestos en esta obra muestran como Andalucía ha experimentado importantes cambios en el consumo cultural a lo largo de los últimos años, bien fruto de los cambios socioeconómicos que nos han ido acercando paulatinamente a la media de consumo y prácticas culturales de los españoles, bien fruto del progresivo proceso de homogeneización cultural de la sociedad actual. Este modelo plantea la imposición de modos de consumir bienes culturales que se han implantado de forma genérica, caso de la pérdida de peso de los soportes físicos frente a los digitales, o la lenta y disruptiva quiebra de un modelo de práctica cultural autóctona.

Para finalizar, esta obra presenta un importante esfuerzo de sistematización y análisis sociodemográfico de unos datos generales, que son descritos y explicados en modo autonómico, y que siguen avanzando un paso más en la importante labor de conexión entre investigación empírica y gestión cultural en Andalucía llevada a cabo por el Observatorio Atalaya.

Ángel Cazorla Martín 